\title{
A PESCA ARTESANAL NA REGIÃo DOS LAGOS: O CASO DO MUNICÍPIO DE PRACUÚBA, AMAPÁ
}

Artisanal fishing in the region lakes: the case of the municipality of Pracuúba, Amapá

Pesca artesanal en la región de lagos: el caso de lo municipio del Pracuúba, Amapá

Resafios

Artigo Original

Original Article

Artículo Original

\section{Diego Maia Zacardi ${ }^{* 1}$, Leandro da Silva Passos ${ }^{2}$, Thibério Carvalho da Silva ${ }^{3}$}

${ }^{1}$ Laboratório de Ecologia do Ictioplâncton e Pesca em Águas Interiores, Universidade Federal do Oeste do Pará, Santarém, Brasil.

${ }^{2}$ Engenheiro de Pesca, Diretor operacional da Caesa, Macapá, Amapá.

${ }^{3}$ Universidade do Estado do Amapá, colegiado de Engenharia de Pesca, Macapá, Amapá.

*Correspondência: Laboratório de Ecologia do Ictioplâncton e Pesca em Águas Interiores, Universidade Federal do Oeste do Pará, Rua Vera Paz (campus Tapajós), bloco 11, sala 04, Salé, Santarém, Pará, Brasil. CEP:68040-255. e-maildmzacardi@hotmail.com

\section{Artigo recebido em 04/06/2020 aprovado em 03/11/2020 publicado em 12/03/2021.}

\section{RESUMO}

O estudo caracteriza o perfil socioeconômico dos pescadores e descreve a atividade pesqueira desenvolvida no município de Pracuúba, Amapá. Na ocasião, foram realizadas entrevistas e aplicação de formulários semiestruturados aos pescadores. A maioria era do sexo masculino, com idade média de 37 anos, baixo grau de escolaridade e renda média mensal declarada pela pesca de três salários mínimos. A pesca ocorre com maior frequência nos lagos Pracuúba e Cujubim, e no rio Flexal. As embarcações mais utilizadas são as canoas movidas a remo, o que limita a prática de captura nas proximidades de suas residências e a utilização do gelo como principal forma de conservação do pescado. A rede de emalhar (malhadeira), o anzol e a zagaia são os apetrechos de pesca mais empregados para capturar tucunarés (Cichla sp.) e apaiari (Astronotus ocellatus). Dentre as principais problemáticas registradas estão: a falta de uma fábrica de gelo, estruturas de desembarque, de fiscalização, estrada para escoamento da produção, ausência de uma política de apoio a atividade pesqueira e a diminuição gradativa das capturas, além dos impactos causados pela criação de bubalinos, afetando a dinâmica do ambiente e consequentemente a vida desses pescadores que possuem a pesca como principal fonte de renda familiar.

Palavras-chave: Pesca de subsistência; Técnicas tradicionais; Recursos pesqueiros; Ambiente lacustre

\section{ABSTRACT}

The study characterizes the socioeconomic profile of the fishermen and describes the fishing activity developed in the municipality of Pracuúba, Amapá. On the occasion, interviews and semi-structured forms were applied to the fishermen. Most were men, with an average age of 37 years, low education and average monthly income declared by fishing for three minimum wages. Fishing occurs more frequently in Pracuúba and Cujubim Lakes, and in the Flexal River. The most widely used boats are paddle-powered canoes, which limits the practice of catching near their homes and the use of ice as the primary form of fish conservation. The gillnet (mesh), fishhook and "zagaia" are the most used fishing equipment to catch "tucunarés" (Cichla sp.) and "apaiari" (Astronotus ocellatus). Among the main problems registered are: the lack of an ice factory, landing structures, inspection, a path for the production flow, the absence of a policy to support fishing activity and the gradual reduction of catches, in addition to the impacts caused by buffaloes, which affect the dynamics of the environment and, consequently, the lives of these fishermen who have fishing as their main source of family income.

Keywords: Subsistence fishing; Traditional techniques; Fishing resources; Lake environment 


\section{RESUMEN}

El estudio caracteriza el perfil socioeconómico de los pescadores y describe la actividad pesquera desarrollada en el municipio de Pracuúba, Amapá. En la ocasión, se aplicaron entrevistas y formas semiestructuradas a los pescadores. La mayoría eran hombres, con una edad promedio de 37 años, baja educación e ingresos mensuales promedio declarados por la pesca por tres salarios mínimos. La pesca ocurre con mayor frecuencia en los lagos Pracuúba y Cujubim, y en el río Flexal. Las embarcaciones más utilizadas son las canoas impulsadas por el remo, lo que limita la práctica de capturar cerca de sus hogares y el uso del hielo como la principal forma de conservación de los peces. La red de enmalle (malla), el anzuelo y el zagaia son los equipos de pesca más utilizados para capturar tucunarés (Cichla sp.) y apaiari (Astronotus ocellatus). Entre los principales problemas registrados están: la falta de una fábrica de hielo, estructuras de aterrizaje, inspección, camino para el flujo de producción, ausencia de una política de apoyo a la actividad pesquera y la reducción gradual de las capturas, además de los impactos causados por la creación búfalos, que afectan la dinámica del medio ambiente y, en consecuencia, la vida de estos pescadores que tienen la pesca como su principal fuente de ingresos familiares.

Descriptores: Pesca del subsistencia; Técnicas tradicionales; Recursos pesqueros; Ambiente lacustre

\section{INTRODUÇÃO}

A atividade pesqueira artesanal realizada no Brasil é diversificada devido a inúmeros fatores como os diferentes ambientes explorados, a variedade de espécies, a sazonalidade de ocorrência, as múltiplas artes de pesca e a frota utilizada. Esses fatores refletem na dificuldade de controle da atividade, que por sua vez desempenha papel fundamental na produção pesqueira nacional, sendo responsável por mais de $45 \%$ do pescado consumido no país (Vasconcellos et al., 2007; Brasil, 2015).

Além disso, a pesca artesanal proporciona aos pescadores um vasto conhecimento sobre os aspectos relacionados ao ciclo de vida das espécies e estratégias de captura, beneficia as populações tradicionais quanto as possibilidades de emprego e renda com grande potencial para o desenvolvimento social e econômico, além de constituir uma ampla diversidade cultural para estas populações (Doria et al., 2012; Serrão et al., 2019a, Zacardi, 2020).

$\mathrm{O}$ ambiente natural de exploração da pesca artesanal sofre constantes mudanças, contudo as atividades estão restritas ao limite imposto pelo meio ambiente, relacionados por vezes ao baixo esforço de pesca e incertezas de clima, tempo, viabilidade de peixes, entre outros fatores que alteram as metodologias de captura utilizadas e as viagens em busca do pescado (Ramires et al., 2012; Zacardi et al., 2014; Zacardi e Silva, 2019).

Segundo Silva et al. (2007) e Hallwass et al. (2013), entender as comunidades e o ambiente em que vivem requer uma série de estudos, nos quais o envolvimento acontece através de dois principais componentes que não estão relacionados e são independentes entre si, como observar o modo de vida da comunidade estudada, compreendendo situações de vivências práticas e conhecer como ocorre a utilização dos recursos naturais locais, bem como a cultura e tradições existentes.

No estado do Amapá, o extrativismo pesqueiro é uma atividade tradicional que tem grande importância socioeconômica, uma vez que a pesca é exercida por centenas de pescadores cadastrados que exploram diversos ambientes aquáticos (região costeira e áreas adjacentes, região dos lagos e bacias fluviais), sendo uma prática predominantemente artesanal de pequena e média escala, que proporciona recurso alimentar e fonte alternativa de renda às comunidades ribeirinhas (Zacardi et al., 2014).

A região dos lagos é uma das áreas estratégicas para a atividade pesqueira (Seap, 2006), possuindo uma extensão de $300 \mathrm{~km}^{2}$, abrangendo os municípios 
de Pracuúba, Amapá e Tartarugalzinho. Apesar da importância e da potencialidade da pesca no estado, o conhecimento técnico e científico sobre a dinâmica desta prática ainda é incipiente e limitada aos trabalhos de Silva e Dias (2010); Santos-Filho et al. (2011), Oliveira et al. (2013), Zacardi (2015) e Daaddy et al. (2016), realidade que acaba comprometendo as ações de gestão e ordenamento dos recursos e da atividade pesqueira regional.

Neste contexto, o trabalho tem como objetivo caracterizar a atividade pesqueira desenvolvida na região dos lagos no município de Pracuúba, Amapá, dada a importância do estabelecimento de ações no gerenciamento da exploração deste sistema de produção.

\section{MATERIAL E MÉTODOS}

O estudo foi realizado na região dos lagos, entre a foz do rio Amapá Grande e a foz do rio Araguari, no município de Pracuúba, situado entre as coordenadas geográficas: $01^{\circ} 44^{\prime} 34^{\prime \prime} \mathrm{N}$ e $50^{\circ} 47^{\prime} 27^{\prime \prime} \mathrm{W}$ (Figura 1). Seus limites são o município do Amapá ao norte, Tartarugalzinho a sudeste, Ferreira Gomes a sul e Calçoene a noroeste.

A região é composta por grandes áreas de floresta, cerrados, áreas inundáveis e complexo sistema de lagos (permanentes e temporários), alimentados por uma densa rede de drenagem influenciada pelos regimes de chuvas regionais. O clima é do tipo equatorial quente e úmido. A temperatura mínima em torno de $20^{\circ} \mathrm{C}$, com a máxima absoluta predominando na faixa de $34^{\circ} \mathrm{C}$.

Os dados foram obtidos por meio de visitas de campo em ações junto à comunidade obtendo-se informações mediante aplicação de formulários semiestruturados, em amostragens não-aleatória intencional (Campos et al., 2019), por meio de abordagens diretas às lideranças, aos pescadores da região e demais atores sociais envolvidos com a prática da pesca. Ressalta-se que no ato de cada entrevista foi apresentado e entregue ao pescador uma via do Termo de Consentimento Livre e Esclarecido (TCLE) com o objetivo de explicar, informar e assegurar os direitos de cada participante.

Figura 1. Localização do município de Pracuúba e região dos lagos, no estado do Amapá, Brasil.

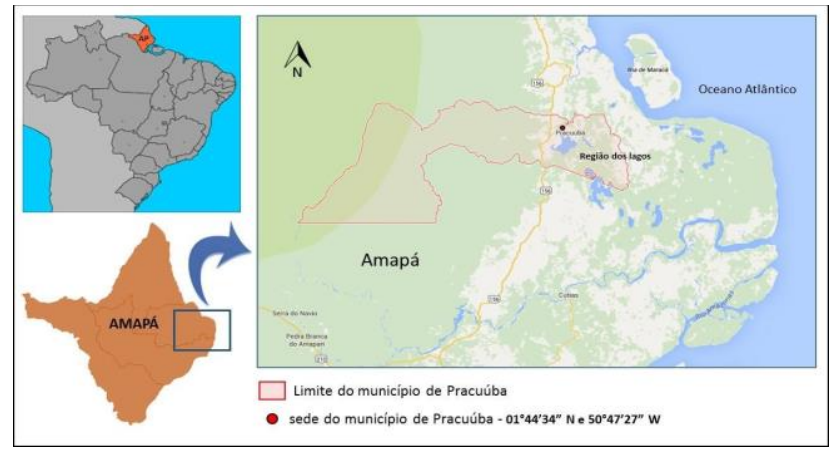

Foram coletados aspectos gerais dos informantes como importância da pesca artesanal no orçamento familiar, relação com outras atividades econômicas, tempo de atividade, frequência das pescarias, métodos e apetrechos utilizados, espécies frequentemente capturadas e as mais comercializadas, época de maior intensidade da pesca, formas de comercialização e conservação do pescado, locais de venda e destino da produção, registrando a realidade do sistema pesqueiro que faz parte de uma atividade econômica que é fonte básica de renda para muitas famílias ribeirinhas do município.

Para definição do tamanho da amostra, considerou-se todos os pescadores que atuam na região dos lagos, como área de pesca, bem como a receptividade dos pescadores abordados no período amostrado, obtendo ao término um total de 37

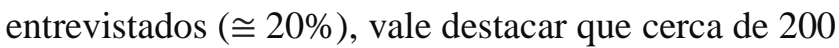
pescadores são cadastrados na colônia de pescadores Z-11, sendo a maioria amapaense.

As informações relativas às temáticas abordadas nos formulários foram tabuladas e agrupadas utilizando o programa Microsoft Office Excel 2016 e os dados analisados de forma descritiva (cálculo de 
frequência, medidas de tendência central e medida de dispersão dos dados), como descrito por Triola (2005) e Fonseca e Martins (2008).

\section{RESULTADOS E DISCUSSÃO}

A tabela 1 apresenta informações referentes aos aspectos sociais, econômicos e culturais dos 37 pescadores artesanais entrevistados. Todos possuíam casa própria providas de energia elétrica e fossas sépticas, somente $30 \%$ alegam possuir abastecimento de água encanada fornecida pela CAESA (Companhia de Água e Esgoto do Amapá) o restante utiliza água de poço e afirmam não utilizar as águas do lago devido à distância das propriedades em relação às margens. As casas dos pescadores de Pracuúba, principalmente as de Cujubim e Pernambuco, são construções de alvenaria, devido projetos de assentamento rural financiado pelo Governo Federal.

Tabela 1. Perfil socioeconômico dos pescadores artesanais entrevistados em Pracuúba, Amapá.

\begin{tabular}{|c|c|}
\hline Informações & Resultados $(n=37)$ \\
\hline Faixa etária & $\begin{array}{l}\text { mínima: } 20 \text { anos } \\
\text { máxima: } 60 \text { anos } \\
\text { média: } 37 \text { anos }\end{array}$ \\
\hline Sexo $(\%)$ & $\begin{array}{l}\text { masculino: } 85 \% \\
\text { feminino: } 15 \%\end{array}$ \\
\hline Escolaridade (\%) & $\begin{array}{l}\text { sem instrução escolar: } 0 \% \\
\text { fundamental completo: } \\
12 \% \\
\text { fundamental incomp.: } 79 \% \\
\text { médio completo: } 6 \% \\
\text { ensino superior: } 3 \%\end{array}$ \\
\hline Estado civil (\%) & $\begin{array}{l}\text { amigados: } 52 \% \\
\text { casados: } 24 \% \\
\text { separados: } 3 \% \\
\text { solteiros: } 21 \%\end{array}$ \\
\hline Filiados a colônia (\%) & $\begin{array}{l}\text { sim: } 93 \% \\
\text { não: } 7 \%\end{array}$ \\
\hline Tempo de pesca (\%) & $\begin{array}{l}\text { até } 10 \text { anos: } 61 \% \\
11 \text { a } 20 \text { anos: } 27 \% \\
21 \text { a } 30 \text { anos: } 9 \% \\
31 \text { a } 40 \text { anos: } 0 \\
\text { acima de } 41 \text { anos: } 4 \%\end{array}$ \\
\hline
\end{tabular}

Os pescadores com mais de 50 anos de idade, contam que os filhos assumem cada vez mais cedo à responsabilidade da pesca e sustento familiar, além da oportunidade de acesso ao benefício do seguro defeso. Entretanto, muitos entrevistados, acusam um aumento de "pescadores" interessados somente no benefício sem praticar de fato a pesca na região e que muitas vezes esses indivíduos nem residem no município.

Observou-se que mulheres auxiliam nas funções da atividade pesqueira, como: auxiliares de pilotagem das embarcações, na retirada dos peixes emalhados e são as principais responsáveis pelos consertos das redes de pesca, exercendo papel relevante na atividade, contudo o marido foi o principal pescador na família.

A maioria dos pescadores afirmaram atuar há menos de 10 anos na atividade pesqueira e alegam conseguir sustentar a família com o lucro da pesca, os quais possuem rendimento médio de três salários mínimos por mês, demonstraram insatisfação 87 concernente às estruturas de porto; da administração da colônia; descaso do poder público com a classe de pescadores; a falta de fábrica de gelo e na demora na entrega das carteiras de pesca.

As embarcações registradas na atividade pesqueira local são exclusivamente canoas de madeira, sem casaria (Fig. 2), com comprimento e capacidade média de $4,5 \pm 1,7 \mathrm{~m}$ e $277 \pm 98,5 \mathrm{~kg}$, respectivamente, $\mathrm{e}$, independentemente do tamanho, conduzem em média, dois tripulantes nas pescarias utilizando a partilha da produção e em alguns casos dividindo os custos como o material de pesca, gelo e combustível. As canoas são utilizadas como base logística durante os dias de pescaria e como local para conservação e transporte da produção. A mão-de-obra utilizada é proveniente da família do pescador como esposa, filhos, irmãos e primos ou vizinhos, indicando que esta atividade apresenta características de cunho familiar. 
Figura 2. Embarcação do tipo canoa de madeira utilizada na região dos lagos, pelos pescadores artesanais do município de Pracuúba, Amapá, Brasil.

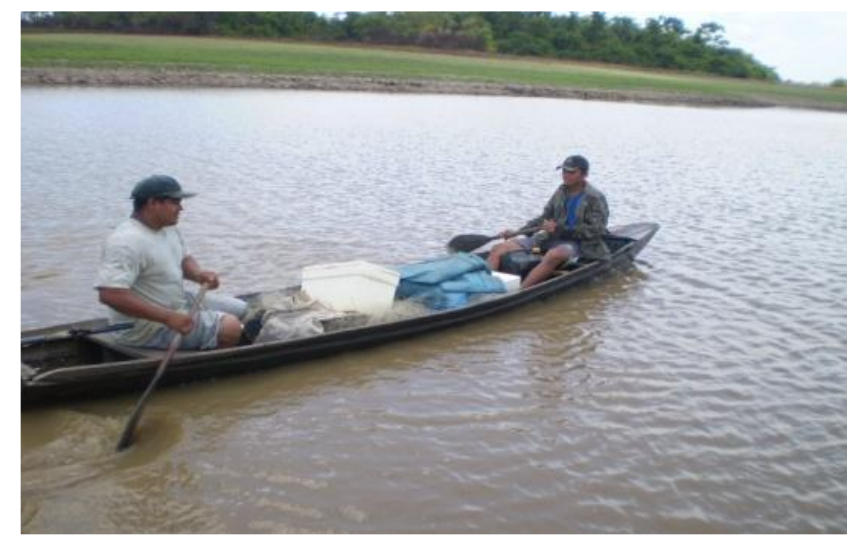

A maioria dos pescadores utilizam as canoas movidas à remo, limitando a prática de captura nas regiões mais próximas de suas residências, essa opção muitas vezes ocorre devido à dificuldade de navegação ou por causa do grande número de macrófitas aquáticas dificultando a utilização de motor. Entretanto, uma pequena parcela de pescadores relatou utilizar motores de propulsão do tipo "rabeta" (com potência variando entre $3,5 \mathrm{HP}$ a $6 \mathrm{HP}$ ), para realizar a atividade em áreas de pesca mais distantes. Além do lago de Pracuúba, os pescadores citam o lago do Cujubim e o rio Flexal, como áreas de pesca. O tempo gasto no deslocamento até a chegada nos locais de pesca, geralmente, ocorre em torno de 30 minutos.

Entre os apetrechos e as técnicas mais utilizadas pelos pescadores de Pracuúba, destacam-se as redes de emalhar ou malhadeiras, linha de mão, zagaia e arpão (Fig. 3). A prática mais corriqueira envolve a utilização de mais de um apetrecho, sendo a rede de emalhar comum em todos os tipos de pescaria.

A rede de emalhar destaca-se por ser o apetrecho mais utilizado e possuem altura e comprimento variável, dispostas verticalmente na coluna d'água por uma série de boias (de isopor) na parte superior, e chumbo ou cabo chumbado na parte inferior. A espessura do nylon e o tamanho da malha dependem das espécies a serem capturadas, são colocadas, geralmente durante o dia, ficando submersa entre oito e doze horas, responsável pela captura de diversas espécies de peixes, como: aracu/piau (Anostomidae), branquinha (Ciurimatidae), pacu e curupeté (Characidae), piranhas (Serrasalmidae), pescada (Sciaenidae), sarda (Pristigasteridae), entre outros.

Figura 3. Apetrechos de pesca utilizados pelos pescadores entrevistados no município de Pracuúba, Amapá. A) rede de emalhar; B) linha de mão; C) arpão (detalhe da ponta) e D) zagaia.

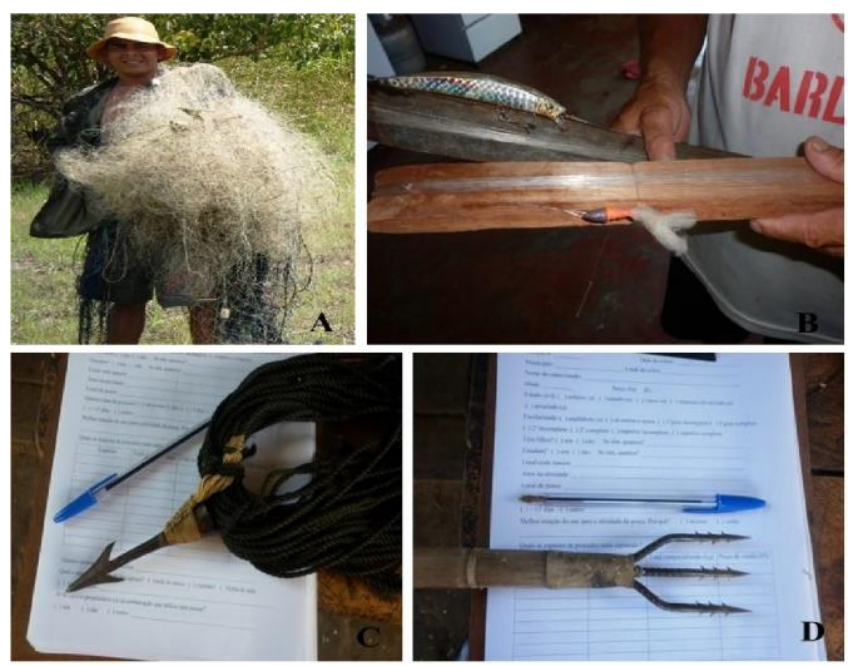

Foram citadas 18 etnoespécies de peixes (variedades, segundo o nome popular) capturados pelos pescadores artesanais: tucunaré (Cichla spp.); apaiari (Astronotus ocelatus Agassiz, 1831); pirarucu (Arapaima gigas Schinz, 1822); traíra (Hoplias malabaricus Bloch, 1794); trairão (Hoplias lacerdae Miranda Ribeiro, 1908); aracu/piau (Schizodon spp.; Leporinus spp.); flexeiras (Hemiodus spp.); acará (Satanoper caacuticeps Heckel, 1840); pacu (Myleus spp.); curupeté (Tometes trilobatus Valenciennes, 1850); piramutaba (Brachyplatystoma vaillantii Valenciennes, 1840); pescada (Plagioscion squamosissimus Heckel, 1840); tamoatá (Hoplosternum littorale Hancock, 1828); jeju (Hoplerythrinus unitaeniatus Agassiz, 1829), sarda (Pellona spp.); piranha (Pygocentrus spp.), branquinha (Curimata inornata Vari, 1989) e mandubé (Ageneiosus inermis Linnaeus, 1766). Entre as espécies citadas, destacam-se o tucunaré e o apaiari 
por apresentarem alto valor comercial e possuírem a preferência dos consumidores.

Em relação aos indivíduos descartados no momento da pesca, foi comum entre todos os pescadores o comportamento de rejeito de peixes juvenis (pequenos) ou de baixo valor comercial. Os principais motivos para a preferência, atualmente, da captura de algumas espécies seria a maior disponibilidade destas no ambiente, além do seu alto valor no mercado. As espécies capturadas sinalizam um forte grau de oportunismo nos hábitos de pesca da comunidade, que adequam os apetrechos e suas especificações à safra esperada.

Após a captura, geralmente, o pescado é eviscerado e lavado, em seguida é armazenado em caixas isotérmicas contendo gelo, onde permanecem até o momento da comercialização. Em função da ausência de porto de desembarque, a produção é desembarcada na areia, à margem do manancial hídrico, próximo à residência dos pescadores. O gelo utilizado pelos pescadores não tem origem de fábrica, apesar de existir uma no município ela encontra-se desativada e sucateada. Atualmente está sendo construída uma nova fábrica de gelo no município, mas enquanto a conclusão e o funcionamento não acontecem os pescadores artesanais de Pracuúba fazem seu próprio gelo ou compram de moradores, gerando um custo maior da atividade pesqueira.

De modo geral, os pescadores utilizam o pescado como alimento (subsistência) e apenas o excedente é comercializado de forma direta, normalmente vendido pelo próprio pescador para moradores e visitantes. Embora, o "atravessador" ainda seja o maior comprador absorvendo $80 \%$ da produção pesqueira do município.

A importância da pesca dentro do município de Pracuúba é inquestionável, seja do ponto de vista econômico ou social. Todavia, tem ocorrido nos últimos anos uma redução das espécies de peixes capturáveis no lago e isso não se aplica a uma única espécie, despertando a preocupação dos pescadores, que acabam por precisar se deslocar para regiões mais afastadas em busca do peixe, aumentando o tempo de pesca e consequentemente os custos da atividade que podem não ser cobertos no momento da comercialização, alguns entrevistados afirmaram que às vezes a pescaria mal dá para a manutenção da família.

Os pescadores apontaram vários fatores responsáveis pela redução do pescado, entre eles: o constante aumento da quantidade de pescadores, a destruição dos habitats naturais pela criação de búfalos, o uso de malhadeiras de malhas pequenas e a falta de fiscalização por parte dos órgãos competentes. O aumento do esforço de pesca, em função do elevado número de pescadores atuantes na região, foi considerado pelos entrevistados, como a principal causa responsável pela redução da produção no lago. Eles explicam, ainda, que o número de pessoas atuando na pesca é muito grande e os recursos já não são suficientes para todos.

Os pescadores apresentam uma opinião crítica a respeito dos problemas existentes em relação à pesca no município, sugerindo alternativas para sua solução ou mitigação como: a criação de políticas ambientais, conscientização e prática da piscicultura, que serviria como um divisor de águas para a produção pesqueira de Pracuúba.

A pesca é uma importante atividade para grande parte da população do município e sua área de entorno, sendo em muitos casos, a principal atividade geradora de renda familiar, demonstrando a importância socioeconômica dentro do contexto local. A atividade é genuinamente artesanal e desenvolvida como forma de subsistência, em que as relações de trabalho, social e de produção se caracterizam pela participação de mão-de-obra familiar ou de grupos de 
vizinhança, apresentando, na maioria das vezes, baixa eficiência de captura.

Pescadores que possuem a atividade pesqueira como principal fonte de renda, geralmente, apresentam dedicação a essa atividade por longo tempo (Rabelo et al., 2017; Corrêa et al., 2018). Essa característica, também, foi observada para a maioria dos pescadores de Pracuúba, que possuem um tempo médio de 10 anos de dedicação na pesca, embora possam exercer outras atividades para complemento de sua renda familiar.

A relação de trabalho familiar constatada no presente trabalho, também foi registrada por SantosFilho et al. (2011); Borcem et al. (2011), Oliveira et al. (2013) e Zacardi et al. (2017). A pesca é uma das poucas atividades que absorve mão-de-obra de pouca ou nenhuma qualificação e sem limites de idade para seus praticantes (Ceregato e Petrere, 2003; Zacardi, 2015; Vaz et al., 2017).

A baixa escolaridade notada entre os pescadores de Pracuúba, reflete na falta de qualificação para praticar outras atividades mais bem remuneradas e limita essas pessoas à atividade pesqueira, como a única oportunidade de emprego. A prefeitura no município funciona como uma das poucas fontes de absorção de mão de obra assalariada, e provavelmente os jovens acabam por ingressar na pesca com intuito de garantir e ajudar o sustento da família.

Dentre as embarcações sediadas no município de Pracuúba e atuantes na região dos lagos, destacamse as canoas movidas a remo ou a motor de propulsão, são de caráter exclusivamente artesanal com alguns aspectos técnicos distintos. Dados similares foram encontrados em outros municípios da região Norte (Oliveira e Frédou, 2011; Borcem et al. 2011; Zacardi et al. 2014).

De modo geral, a dinâmica da atividade e do mercado pesqueiro, pode ser caracterizada como uma pesca de pequena escala, com uso de um ou a combinação de vários apetrechos de pesca simples e em viagens, de curta e/ou média distância. O pescado comumente é comercializado aos atravessadores na própria localidade, na maioria das vezes fresco e eviscerado, quando necessário utilizam o gelo para resfriar e manter a integridade do produto.

O tipo de conservação do pescado relatado neste trabalho corrobora com aqueles apresentados por Isaac et al. (1998) e Silva e Silva (2006), mas a conservação do pescado varia de acordo com a distância do local de pesca e as condições econômicas do pescador.

O atravessador é uma função presente em praticamente todas as relações comerciais nas quais o pescado está envolvido, especialmente na região norte do País. Essa forma de comercialização sempre está vinculada à exploração, elevação de preço do pescado até o consumidor final e a criação de uma ligação de dependência econômica.

A dependência do pescador em relação ao 90 intermediário é decorrência da falta de uma melhor estrutura de desembarque, armazenamento e distribuição de gelo fazendo com que o intermediário dite os preços, comprometendo sua rentabilidade dentro da cadeia produtiva. Essa prática resulta da falta de organização dos pescadores como um segmento social, sendo prejudicial pela diminuição do lucro e elevação do custo do pescado para o consumidor final. De acordo com Moraes et al. (2010) os pescadores que conseguem ter acesso direto ao consumidor final ou uma proximidade maior com o destino do pescado, conseguem alcançar melhores preços de venda.

A região dos lagos, configura-se como uma das principais área para pesca de recursos continentais no estado do Amapá, somado a bacia hidrográfica do rio Araguari e outros afluentes da região. Os pescadores realizam pescarias diversificadas, caracterizadas por uma complexa base de informação influenciada por costumes tradicionais. 
Por meio da pesca artesanal os pescadores exploram o meio aquático de forma peculiar e mantêm grande diversidade de interações com o ambiente (Serrão et al., 2019b; Zacardi, 2020), principalmente aqueles que têm a pesca como única atividade, tornando-se os parceiros naturais de qualquer processo de conservação ambiental e são os mais comprometidos com a causa. Essa forte dependência do uso dos recursos naturais que garanta a subsistência e economia das comunidades, justifica o sentimento de conservação do recurso relacionado à garantia de sobrevivência.

As pescarias artesanais podem exercer impactos consideráveis sobre os ecossistemas lacustre, afetando, em cadeia, praticamente todos os processos ecológicos nesses ambientes. Dessa forma, para obter sucesso no gerenciamento dos recursos naturais e deste tipo de pesca, deve-se refletir na mudança de táticas e estratégias, passando da pura avaliação do recurso pesqueiro, para a avaliação da atividade pesqueira como um todo, buscando uma abordagem integrada das informações científicas, como afirma Doria et al. (2012) para a realidade em algumas regiões da Amazônia.

Essa característica difusa da pesca artesanal torna a gestão do setor extremamente difícil por causa da falta de informações confiáveis sobre o número de pescadores e a magnitude de sua produção pesqueira (McGrath et al., 2008).

É indiscutível a importância social e econômica desta atividade para a região dos lagos do Amapá, despontando a necessidade de que sejam tomadas decisões públicas, uma vez que já se têm indicativos de incapacidade de suporte destas pescarias. Assim, medidas de ordenação e manejo relacionadas com os estoques capturáveis é essencial para a manutenção desta atividade na área de estudo.

Apesar do reconhecimento e da importância da atividade pesqueira para o desenvolvimento socioeconômico do estado, observa-se na maioria dos casos o descaso por parte dos órgãos responsáveis pelo setor (falta de embarcações, de tecnologia de pesca, de financiamento), bem como um adequado entreposto de pesca (Isaac et al., 1998). Os espaços de discussão coletivos ampliam a participação dos pescadores em diferentes estágios de construção de políticas do setor, como na formulação, implantação e fiscalização.

Historicamente, há uma deficiente participação dos segmentos sociais da pesca nos processos de decisão (Silva, 2014), sendo esta a maior fragilidade dos insucessos na gestão dos recursos pesqueiros no Amapá e no Brasil de forma geral. Assim, a regulamentação da utilização sustentável deste importante setor Amapaense deve respeitar as características regionais com base em estudos locais e experiências globais.

É importante que sejam adotadas políticas governamentais e não governamentais, para manutenção do sistema, como fortalecimento da classe de pescadores e melhoria da qualidade de vida através de investimentos em educação formal, profissional e ambiental; estímulo e investimento em empreendedorismo na pesca artesanal, além de promoção à participação nas tomadas de decisões, tornando o grupo mais consciente, fortalecido e eficiente.

A desarticulação institucional, o paternalismo governamental e a falsa legitimidade de muitas lideranças pesqueiras são um dos maiores entraves do setor, pois a pouca informação e o baixo grau de escolaridade das comunidades são aproveitados para torná-las massa de manobra para interesses nãocoletivos. Silva (2014) comenta que a mobilização social implica numa mudança profunda, principalmente na legitimidade dos representantes dos atores envolvidos diretamente com a pesca, para poder promover uma nova base de governança e a melhor estratégia para isso é estimular a formação, no âmbito 
estadual e municipal, de fóruns de discussão e negociações voltados ao gerenciamento participativo do setor pesqueiro.

Por fim, recomenda-se, que sejam feitos esforços para a consolidação de um arranjo institucional contínuo com elevado nível de consciência e a promoção de mais espaços de discussão com os pescadores, fortalecendo o capital social e, assim, avançar no desenvolvimento da comunidade pesqueira da região.

\section{CONCLUSÃO}

A atividade pesqueira artesanal praticada no município de Pracuúba não é apenas uma forma de obtenção de renda, mas um modo de subsistência fundamental que precisa ser preservado. A pesca é praticada em embarcações pequenas com pouca autonomia, sendo realizada por um grupo social preocupado em gerenciar e cuidar do recurso pesqueiro, contribuindo de forma sustentável. Ressalta-se, portanto a importância da realização de um estudo integrado (recursos pesqueiros, pescadores e ambiente) buscando subsídios ao ordenamento e manejo da atividade pesqueira na região.

Registrou-se o predomínio no uso de apetrechos de pesca com destaque para a utilização da rede de emalhar e preferência por captura de alguns peixes de alto valor comercial e de maior preferência dos consumidores, como o tucunaré (Cichla sp.) e o apaiari (A. ocellatus). O município não possui portos de desembarque, não oferecem infraestrutura de armazenamento, conservação e acesso para o escoamento da produção, sendo comercializada direto aos atravessadores.

É importante salientar a necessidade de desenvolvimento de maiores levantamentos de informações sobre a atividade pesqueira e que se faça estudos de dinâmica populacional das espécies capturadas, visando avaliações mais consistentes dos estoques explorados que proporcionem a elaboração de instrumentos de planejamento para gestão pública.

Aconselha-se a continuidade dos levantamentos socioeconômicos e da atividade pesqueira, assim como a coleta de dados de produção e esforço junto aos pescadores, além de estudos de biologia populacional das principais espécies ícticas visando avaliações mais consistentes dos estoques pesqueiros, proporcionando a elaboração de instrumentos de planejamento para gestão pública que sirvam para nortear as atividades produtivas, garantir a sustentabilidade e promover a qualidade de vida.

\section{AGRADECIMENTO}

Os autores agradecem a Universidade do Estado do Amapá (UEAP) pela cessão da infraestrutura para o desenvolvimento do estudo e a todos os pescadores e moradores do município de Pracuúba que forneceram as informações, sem as quais esse trabalho não poderia ser realizado.

Todos os autores declararam não haver qualquer potencial conflito de interesses referente a este artigo.

\section{REFERÊNCIAS}

BORCEM, E.R.; FURTADO-JÚNIOR, I.; ALMEIDA, I.C.; PALHETA, M.K.S.; PINTO, I.A. A atividade pesqueira no município de Marapanim-Pará, Brasil. Revista de Ciências Agrárias, v.54, n.3, p. 189-201, 2008.

BRASIL. Despesas com o pescador artesanal no município de Pentecoste no ano de 2015. [Portal da Transparência]. Ministério da Transparência, Fiscalização e Controladoria-Geral da União. https://www.portaltransparencia.gov.br/defeso/defeso ListaMunicipios.asp? $\mathrm{UF}=\mathrm{CE} \& \mathrm{Pagina}=1 \&$ TextoPesq uisa=pentecoste (acessado em 08/03/2020).

CAMPOS, D.P.F.; COÊLHO, Y.K.S.; SERRÃO, E.M.; ZACARDI, D.M. Problemáticas e conflitos socioambientais da pesca praticada no lago Maicá, Santarém, Pará. In: J.C. RIBEIRO; C.A. SANTOS (eds.), A face multidisciplinar das ciências agrárias 2. Belo Horizonte, Atena editora, p. 13-24, 2019. 
CEREGATO, S.A.; PETRERE, M.J. Financial comparisons of the artisanal fisheries in Urubupungá Complex in the middle Paraná River (Brazil). Brazilian Journal of Biology, v.63, n.4, p.673-682, 2003.

CORRÊA, J.M.S.; ROCHA, M.S.; SANTOS, A.A.; SERRÃO, E.M.; ZACARDI, D.M. Caracterização da pesca artesanal no Lago Juá, Santarém, Pará. Revista Agrogeoambiental, v.10, n.2, p.61-74, 2018.

DAADDY, M.D.V.; SANTOS, C.; BRANDÃO, R.M.L.; AMANAJÁS, R.D.; RIBEIRO, A.N.N. Pesca do apaiari, Astronotus ocellatus (Agassiz, 1831), e perfil socioeconômico dos pescadores artesanais de uma região da Amazônia brasileira. Boletim do Museu Paraense Emílio Goeldi, v.11, n.2, p.363-378, 2016.

DORIA, C.R.C.; RUFFINO, M.L.; HIJAZI, N.C. A pesca comercial na bacia do rio Madeira no Estado de Rondônia, Amazônia. Acta Amazonica, v.42, n.2, p.29-40, 2012.

FONSECA, J.S.; MARTINS, G.A. Curso de Estatística. São Paulo, Atlas, 2008.

HALLWASS, G.; LOPES, P.F.; JURAS, A.A.; SILVANO, R.A.A. Fishers' knowledge identifies environmental changes and fish abundance trends in impounded tropical rivers. Ecological Applications, v.23, n.2, p.392-40, 2013.

ISAAC, V.J.; ARAÚJO, A.R.; SANTANA, J.V. A pesca no Estado do Amapá: Alternativas para o seu desenvolvimento sustentável. Série estudos do Amapá. Amapá, 138 p., 1998.

MCGRATH, D.G.; ALMEIDA, O.; VOGT, N.; PORTILHO, A. Diagnóstico, tendências, potencial, estrutura institucional e políticas públicas para o desenvolvimento sustentável da pesca e aquicultura. In: F.L. FRÉDOU; O.T. ALMEIDA; K. MOURÃO; K. BARBOSA; S. RIVERO; R. THOMPSON, R. (Eds.). Diagnóstico da pesca e da aquicultura no Estado do Pará. Belém, Secretaria de Pesca e Aquicultura do Estado do Pará, p.1-117, 2008.

MORAES, A.O.; SCHOR, T.; ALVES-GOMES, J.A. Relações de transporte na pesca de bagres no Rio Solimões - AM. Novos Cadernos NAEA, v.1, n.3, p. 155-170, 2010.

OLIVEIRA, D.M.; FRÉDOU, F.L. Caracterização e dinâmica espaço-temporal da atividade pesqueira na baía de Marajó - estuário amazônico. Arquivos de Ciências do Mar, v.44, n.3, p.40-53, 2011.

OLIVEIRA， J.C.S.; VASCONCELOS， H.C.G.; PEREIRA, S.W.M.; ISAAC, V.J.; JUNIOR-TELES,
A.P. Caracterização da pesca no Reservatório e áreas adjacentes da UHE Coaracy Nunes, Ferreira Gomes, Amapá - Brasil. Biota Amazônia, v.3, n.3, p.83-96, 2013.

RAMIRES, M.; BARRELLA, W.; ESTEVES, A. Caracterização da pesca artesanal e o conhecimento pesqueiro local no Vale do Ribeira e litoral sul de São Paulo. Revista Ceciliana, v.4, n.1, p.37-43, 2012

RAMIRES, M.; MOLINA, S.M.G.; HANAZAKI, N. Etnoecologia caiçara: o conhecimento dos pescadores artesanais sobre aspectos ecológicos da pesca. Biotemas, v.20, n.1, p.101-113, 2007.

SANTOS-FILHO, A.P.; SILVA, L.M.A.; BITTENCOURT, S.C.S.; NAKAYAMA, L.; ZACARDI, D.M. Levantamento socioeconômico da atividade pesqueira artesanal na vila do Sucurijú, Amapá, Brasil. Boletim Técnico-Científico do CEPNOR, v.11, n.1, p.129-141, 2011.

SEAP. Registro geral da pesca, resultados do recadastramento nacional dos pescadores do Brasil. Secretaria de Aquicultura e Pesca, Brasília, 104 p., 2006.

SERRÃO, E.M.; BRAGA, T.M.P.; COÊLHO, Y.K.S.; CAMPOS, D.P.F.; IMBIRIBA, L.C.; SUZUKI, M.A.L; PONTE, S.C.S.; ZACARDI, D.M. (2019a). Caracterização da pesca e percepção ambiental de pescadores de um lago de inundação no Baixo Amazonas: Perspectivas para o manejo. In: A.C.B. LIMA; O.T. ALMEIDA (Orgs.). Uso de recursos naturais na Amazônia: experiências locais e ferramentas para governança. Belém, GAPTA/UFPA, p. 49-87, 2019a.

SERRÃO, E.M.; RABELO, Y.G.S.; CÔRREA, J. M. S.; ZACARDI, D.M. Caracterização da atividade pesqueira em dois lagos de inundação amazônico, Santarém, Pará. In: J.C. RIBEIRO; C.A. SANTOS (Orgs.). A face multidisciplinar das ciências agrárias 2, Belo Horizonte, Atena editora, p. 1-12, $2019 b$.

SILVA, L.M.A.; DIAS, M.T. A pesca artesanal no estado do amapá: estado atual e desafios. Boletim Técnico e Científico do Cepnor, v.1, 0n.1, p.43-53, 2010.

SILVA, A.P. Pesca artesanal e empresas de petróleo: a abordagem participativa como proposta de desenvolvimento no Baixo-Sul da Bahia, Brasil. Cadernos Gestão Social, v.5, n.1, p.13-29, 2014.

SILVA, M.C.; OLIVEIRA, A.S.; NUNES, G.Q. Caracterização socioeconômica da pesca artesanal no município de Conceição do Araguaia, Estado do Pará. 
Amazônia: Ciência \& Desenvolvimento, v.2, n.4, p.37-51, 2007.

TRIOLA, M.F. Introdução à Estatística. Rio de Janeiro, LTC Editora, 2005.

VASCONCELLOS, M.; DIEGUES, A.; SALES, R. Limites e possibilidades na gestão da pesca artesanal costeira. In: A. Costa (Ed.). Nas redes da pesca artesanal. Brasília, Ibama, p.15-84, 2007.

VAZ, E.M.; RABELO, Y.G.S.; CORRÊA, J.M.S.; ZACARDI, D.M. A pesca artesanal no lago Maicá: aspectos socioeconômicos e estrutura operacional. Biota Amazônia, v.7, n. 4, p.6-12, 2017.

ZACARDI, D.M. Aspectos social e técnicos da atividade pesqueira realizada no rio Tracajatuba, Amapá, Brasil. Acta of Fisheries and Aquatic Resources, v.3, n.2, p.31-48, 2015.

ZACARDI, D.M. A pesca artesanal em áreas de inundação no Baixo Amazonas, Pará: técnicas de captura e composição pesqueira. In: L.N. MENDES(Org.). Aquicultura e Pesca Adversidades e Resultados 3, Ponta Grossa, Atena editora, p. 1-16, 2020.

ZACARDI, D.M.; MOTA-SILVA, F.J. A pesca no rio Arapiuns: estudo de caso com os pescadores da comunidade Vila Brasil, Santarém, Pará. In: R.R.S. SILVA-MATOS; H.A.F.; ANDRADE, N.A.F. MACHADO (Orgs.). A face multidisciplinar das ciências agrárias 3, Ponta Grossa, Atena editora, p. 620, 2020.

ZACARDI, D.M.; PONTE, S.C.S.; SILVA, A.J.S. Caracterização da pesca e perfil dos pescadores artesanais de uma comunidade às margens do rio Tapajós, Pará. Amazônia: Ciência \& Desenvolvimento, v.10, n.19, p.129-148, 2014.

ZACARDI, D.M.; SARAIVA, M.L.; VAZ, E.M. Caracterização da pesca artesanal praticada nos lagos Mapiri e Papucu às margens do rio Tapajós, Santarém, Pará. Revista Brasileira de Engenharia de Pesca, v.10, n.1, p.31-43, 2017. 